International Journal of Advanced Chemistry, 9(1) (2021) $44-48$
International Journal of Advanced Chemistry
SPC
Website: www.sciencepubco.com/index.php/IJET
Research paper

\title{
Paper bacterial battery based on polymer as degradable sources of energy
}

\author{
Azhar M Haleem ${ }^{1} *$, Ruaa H Abass ${ }^{2}$, Israa M Haleem ${ }^{3}$ \\ ${ }^{1}$ Environmental Research Center, University of Technology, Baghdad, Iraq \\ ${ }^{2}$ University of Al-Farahidi, collage of Dentistry, Baghdad, Iraq \\ ${ }^{3}$ College of Agricultural Engineering Science, Dept. of Animal Resources, Baghdad, Iraq \\ *Corresponding author E-mail: amhjanabi74@gmail.com
}

\begin{abstract}
Paper bacterial battery (PBB) is a sustainable source of bioenergy derivate from bacterial activities, paper bacterial battery or microbial fuel cell has unique features like biodegradable, cost- affordable, energy- effectiveness, and environmental sounds beside of complete control by produced energy by increasing the number of folds and can made it in shapes and sizes appropriate for all use and type of devices, which is characterized by high flexibility and wide uses. The current study described in detail the fabrication steps of a simply biodegradable paper battery that mainly composed of a substrate of cellulose, Poly (amic) acid (PAA) and polyvinyl alcohol (PVA) as reducing and stabilizing agent, immobilization matrix, for bacterial cells stability, this degradable network provides oxygen-blocking and proton exchange membrane (PEM). The fabricated bacterial battery gave power of $3.5 \mu \mathrm{W} / \mathrm{cm} 2$ and a current quantity of $127 \mu \mathrm{A} / \mathrm{cm} 2$, this generated power can be enhancement by more folding or compacting of the fabricated paper-polymer unit.
\end{abstract}

Keywords: Paper Bacterial Battery; Biodegradable; Microbial Fuel Cell; Sustainable Energy; Green Electronics.

\section{Introduction}

Energy production and waste administration are two important requests for sustainable societies. Paper Bacterial Battery (PBB) may provide the ideal solution for combining these two approaches [1], unique properties of promising batteries such as high energy productivity, micro sizes, and biodegradation make scientists have worked to achieve them in future batteries to align with the shapes and sizes of portable electronic devices for the most promising technologies in the fields of communications, medical and other sciences [2].

Paper Bacterial Battery (PBB) is completely built from biodegradable material have flexibility, with ultra-thin design fabricated by combining carbon nanotubes with a classical layer of cellulose-based paper, to obtain unusually thin, and safe uses, enabling integration into a wide range of products [3-6]. Their uses is alike to traditional chemical batteries with the sufficient differences that they are non-corrosive and don't need large housing [7].

Among all the electronic waste, energy storage devices still the most important because of their toxic metals and high reactivity [8], nonbiodegradable lithium-ion batteries, and super capacitors are considered as the hopeful batteries for flexible and transportable devices because of their high effectiveness, lightweight, density, and ability to be linked into different substrates, but their toxic inorganic substances that cause environmental destruction and real treatments are required before disposal and landing, it has prompted serious thinking for more environmentally friendly alternatives to energy harvesting technologies such as solar cells, biodegradable batteries and nanogenerators [7-9]. Esquivel etal designed a single-use biodegradable battery can be disposed to the soil without further treatment, this could be the beginning of a new age of green electronics [4]. In the current study we designed a self-sustaining microbial paper battery it mainly depends on the ability of bacteria to convert the energy stored in organic matter into electrical energy in a low-oxygen ambience. The bacterial viability could be sustained by providing it with any organic source. Moreover, the bacterial cells that used to generate electrical energy can be adapted to degrade the same battery material so should be used bacterial isolates have the ability to decomposed toxic substances to reduce recycling and discharging cost [10]. Cellulose-based bacterial battery is a revolution in green electronics [11], because of unique cellulose properties like biodegradable, low cost, flexibility and light weight all these qualities represent a suitable substrate for making biodegradable batteries, and the only confrontation is the high porosity that permits oxygen to pass through easily. So, the current substrate provide minimum oxygen permeation and boost proton- transferring efficiency, by engineered arrangement of these mixed substrates that have high biodegradation in aqueous media of this biobattery.

\section{Materials and methods}

\subsection{Installation of mixed paper PAA- and PVA polymers}


To prepare a non-porous and gas-transfer blocking surface, a mixture of one part of PAA gel was added to five parts of PVA aqueous solution provided with Glutaraldehyde (GA) with final concentration $0.5 \%(\mathrm{w} / \mathrm{w})$, the viscous mixture was stirred till obtaining a nonliquid gel, which was then poured on a clean glass surface in one continuous and homogeneous layer after which the previous printed wax Whatman filter paper was placed on this layer with light pressure to allow the components to settle on the paper to obtain a homogeneous and non-porous surface.

\subsection{Prepare of cathode/anode electrodes}

The second functional paper was prepared by spraying a mixture of nickel and binder solution $(1000 \mu \mathrm{L}$ of $5 \mathrm{w} \% \mathrm{Nafion}, 100 \mu \mathrm{L} \mathrm{DW}$, $500 \mu \mathrm{L}$ isopropanol) on well waxed PEM filter paper that submit good cathode conductivity, the anode was constructed by printing carbon nanotube-based inks on the surface of the paper, the copper strip added to provide a conductive bridge between two electrodes (cathodeanode), all functional papers were glued together with an adhesive material

\subsection{Prepare of bacterial suspension}

Previously isolated and diagnosed Shewanella sp. Bacteria were used as a source of electrons in the current paper-based battery. Bacterial cells were activation by inoculating $100 \mathrm{~mL}$ of nutrient broth medium and incubating for 24 hours at $35^{\circ} \mathrm{C}$ with slow shaking, bacterial cells harvested by centrifugation at 5,000rpm for $3 \mathrm{~min}$ the, bacterial pellet loaded in the anodic reservoir.

\subsection{Measures of electrical}

The potential of electrical power was assessed by data acquisition (NI USB-6363). The resulting voltages were checked each five seconds and registered by a customized LabVIEW interface. Currents and energies within outer resistors were measured from the voltages.

\subsection{Electrochemical impedance spectroscopy (EIS) assessment}

We measured The EIS by AutoLab PGSTAT100N 100 V / 250 mA, Metrohm. Two electrode setups were used for all apparatuses, resulting data were listed within Frequency range $10 \mathrm{kHz}-32 \mathrm{MHz}$ with an AC signal of $10 \mathrm{mV}$ capacity.

\subsection{Biodegradation of the battery material}

After the depleted of the fabricated biobatteries, they weren't exposed to additional treatments, but they were soaked in water at room temperature for different times $(7,14$, and 21$)$ days, benefiting from the bacteria loaded on the material of the battery in the degradation process, then the soaked batteries were taken and dried for 24 hours at room temperature and the weight was measured after treatment. Weight differences represent the degradation efficiency.

\section{Results and discussions}

Cellulose can be considered an attractive factor in the manufacturing of batteries for flexible electronic devices due to its unique properties and its ability to degradation [12-14], which reduces electronic waste, and can utilize it in fabricate many functional layers such as catalysts, electrodes, separator, and reservoirs, (Figure 1) demonstrated a cellulose paper used as a substrate for paper bacterial battery (PBB), the papery cellulose filling represents an appropriate surface for loading the bacterial suspension through the capillary properties of the cellulose [15]1 [6], moreover easy to stack and can be combined into more than one interface, also Wax-treated cellulose function layer represents a convenient and effective medium for transporting protons and blocking electrons [10], cellulose also provides a wide range of options for manufacturing low-cost, bio-efficient, and environmentally friendly functional papers [17 and 18]. By shaping their delocalized electron systems, the integrated polymers were used for different purposes like electrodes, electro catalytic, and chemical separation [19]. PAA and PVA were used as carbonyl reference because of its nature as high electronegative [10]. Rich functional collections, like carboxyl, amine, and phenyl groups, give the polymers competence and eligibility for more qualifications to satisfy various demands for various applications [17] and [19]. Moreover, those polymers have great binding ability to the cellulose fibers making these mix substrates interesting to prospective electronic progress [20].

\subsection{The oxygen blocking layer}

As we previously mentioned, the structure and porosity of the cellulose substrate represents a suitable medium for the attachment of bacterial cells, but they do not prevent the transfer of electrons that could lead to diffusion of oxygen to the anode and causes low battery performance and reduction the time of operating [21], (Figure 1) shows a various treatment of paper-based substrates battery. The PBB utilized printing carbon nanotube-based inks on the surface of the paper anodes for bacterial attachment and paper reservoirs for holding the anolyte and catholyte for an extended period of time, waxed paper was used as a PEMs to minimize the transferring from anolyte and catholyte but permitting protons moving through it [22], uses of Nafion 117 as sporting for a PEM layer raises the biobattery efficient and provide height volumetric value change with increasing humidity, but now day expensive commercial Nafion 117 was replaced with low cost materials for fabrication of bacteria-powered battery such as chemically treated papers [22]. The main goals for using waxed paper as PEM layer are inexpensive, have high hydrophobicity to separate anode and cathode halls, porous nature for cellulose paper gave additional advantages for electron manipulation and ion transport across the entire paper and considered a good medium for bacterial respirations. The PBB performance was evaluated by measuring the potential between cathode and anode in open- circuit by using data acquisition (NI USB-6363). The resulting voltages were checked each five seconds and registered by a customized LabVIEW interface. The current flow was started immediately after resistor joined between anode and cathode, the non- waxed filter paper gave significant lower current than others, and this may be result from low proton exchange rate, while waxed paper gave good current flow than non- waxed paper but Nafion 117 treated paper was the highest (Figure2). From the results shown in (Figure 2B), can be noted that the efficiency of the filter paper increases gradually with the progress of treatment by increasing the separation efficient between both anode and cathode champers and 
reached the highest levels in the fifth treatment by adding Nafion 117, but when testing each material alone, it was found that the height PEM was measured in Nafion 117 (611.66 mV) followed by PVA- paper treated (355mV).

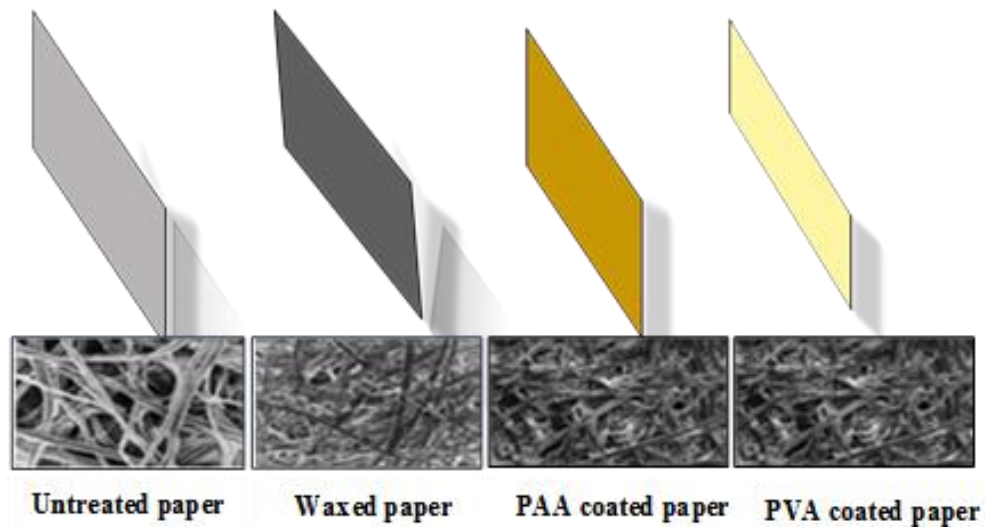

Fig. 1: SEM Images of (A) Untreated Cellulose Paper, (B) Waxed Cellulose Paper, (C) PAA-Coated Paper, and (D) PVA-Coated Paper.
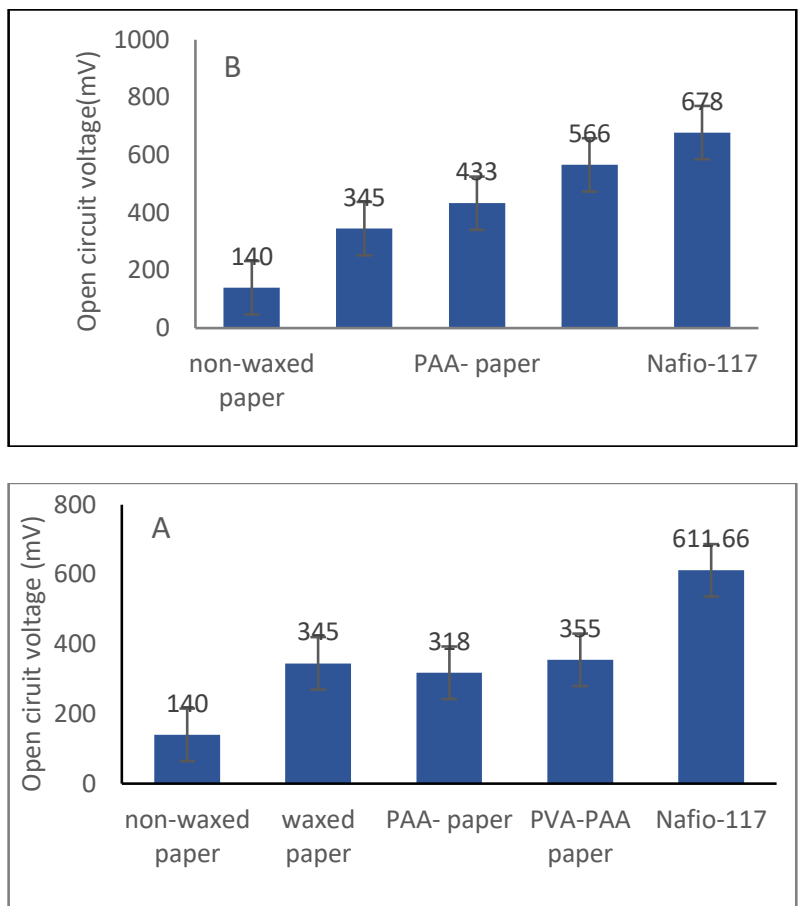

Fig. 2: (A) Open Circuit Voltages for Five Shapes of Treated Paper with Different Pems (1: Non-Waxed Paper, 2: Waxed Paper, 3: PAA-Paper, 4: PVAPaper, 5: Nafion117-Paper) (B) Open Circuit Voltages After Serial Treated for Whatman Filter Paper.

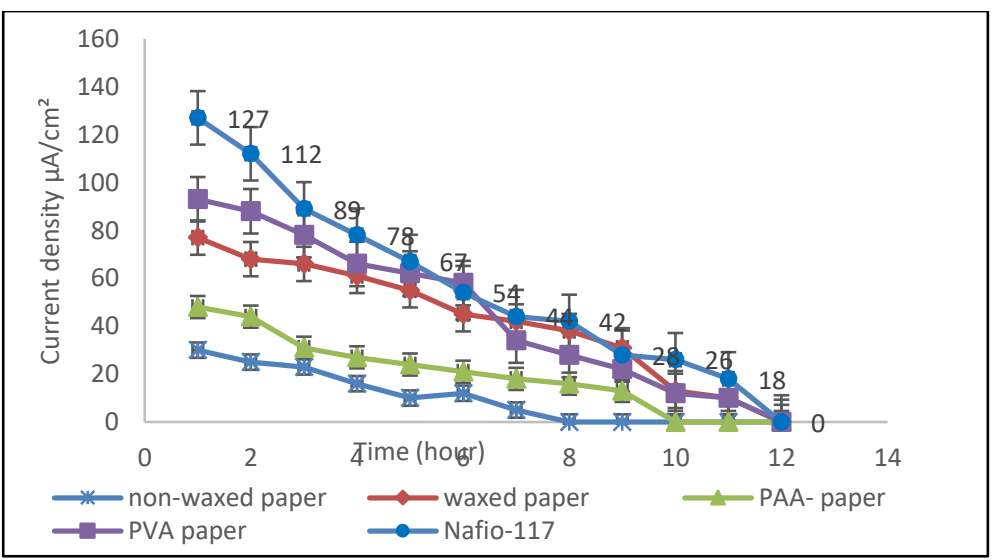

Fig. 3: Resulting Currents $\left(\mu \mathrm{a} / \mathrm{Cm}^{2}\right)$ from Five Paper-Based Batteries at Various Pems (1: Non-Waxed Paper, 2: Waxed Paper, 3: PAA-Paper, 4: PVAPaper, 5: Nafion117)

\subsection{Principles of PBB operating}

The paper bacterial battery (PBB), mainly consists of the anode and the cathode chamber, separated from each other by (PEM), allows the passage of $\mathrm{H}^{+}$and other cations from anode to the cathode with the presence of external conducting load that can be connect the two electrodes to complete the electrical circuit [23]. The bacterial cells oxidize the organic matter in the anode chamber and transfer the flow of electrons resulting from the microbial respiration, during this process, the chemical energy is captured through the electron transport 
chain by two co-enzyme function Nicotinamide adenine dinucleotide (NAD+) and Nicotinamide adenine dinucleotide dehydrogenase (NADH) and producing biological energy shape adenosine triphosphate (ATP) [24 - 27].

In the current form of the microbial fuel cell (MFC), the carbon nanoparticle printing ink was used for bacterial cells attachment, to reduce the manufacturing cost waxed whatman filter papers were used as PEMs, but the expensive material Nafion 117 was used for comparison. The current paper battery gave high power and current quantities and worked for more than 12 hours to reach to zero current, that is 48 fold higher than the early conceptual the paper battery [15]. More investigated studies should be carried out for proton exchange dynamics through different designed papers as PEMs, PVA-treated whatman filter papers seems to be suitable, cheap, and acceptable performance PEM. From previous studies, the SEM images showed that bacterial cells constituting the biofilm remain attached to the paper fibers rather than on the carbon reservoir (nanocarbon tubes or carbon cloth) because of the high wicking capability of the paper. After making sure that the filter papers treated with wax and polymers (PAA and PVA) can be a desirable substrate in bacteria-dependent batteries. four fabricated batteries joined together to create a wanted power to operate red LED (HLMP-P156, Digikey) for above 20 minutes, after the LED lightning the voltage level through each one of batteries, and in the series of batteries combined during the operation time was recorded (Figure 4), it is worth noting that it did not happen voltage reversal in each individual battery this explains the insulation efficiency provided by the hydrophobic fabricated layer.

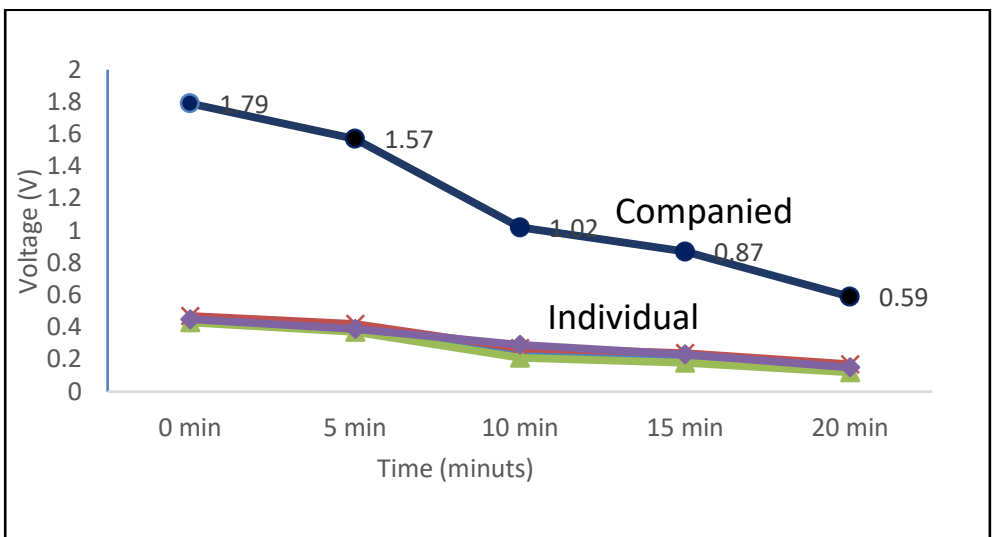

Fig. 4: Voltage Values (V) of the Companied Batteries and Individual Ones Connected with A LED Were Measured at Different Time

\subsection{Biodegradation}

Simply, the fabricated biobattery can be degraded during a period ranging from 7-14 days after being dipped in water and as shown in the Figure (5) through a change in weight before and after dipping. What helped in the process of decomposition is the presence of bacteria in the material of the battery, however, need more studies that clarify the mechanism of degradation in a way Completely in different conditions, such as bacteria species, temperature, dipping time and the presence or absence of additional nutrients, all of which help to understand the mechanism of degradation.

(A)

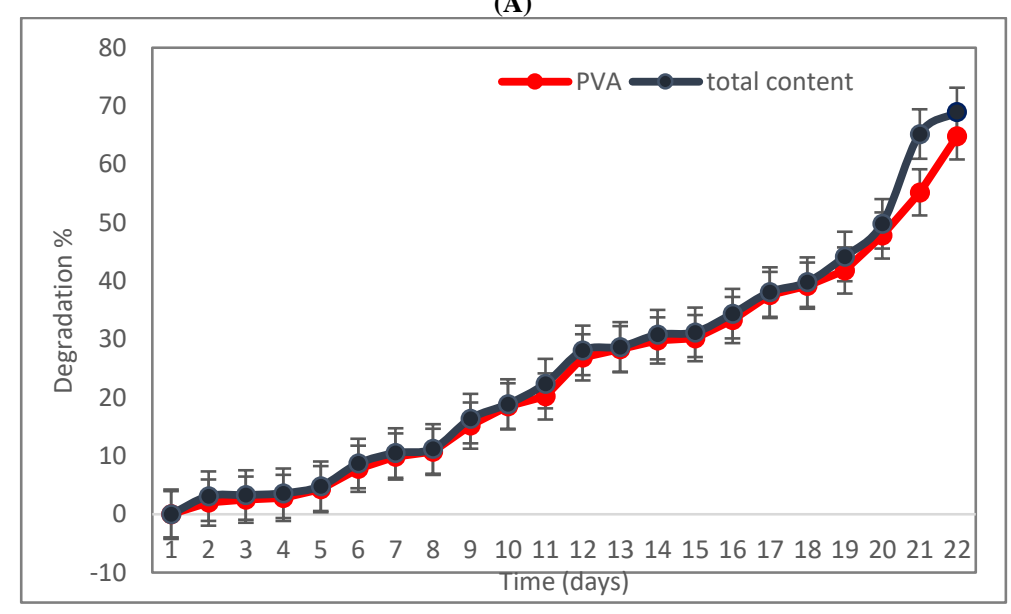

(B)
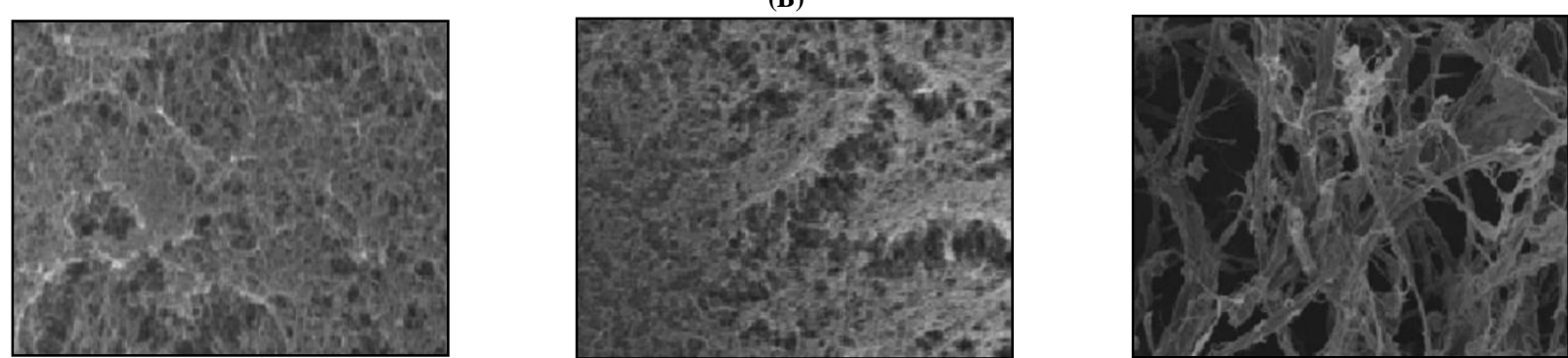

Fig. 5: (A) Biodegradation Rate (\%|) of Fabricated Paper Battery at Different Time (0-21) Days (B) SEM Images of the Biodegradation Method for Fabricated Paper Battery at Different Time (0,7, and 14) Days. 


\section{Conclusions}

The current study described the practical steps of designing and operating paper bacterial battery which has the ability to operate the electronic device for 20 minutes, the fabricated battery fully biodegradable with achieving sustainability by reducing the daily consumption of electric energy beside their economic acceptability, Depending on the available data on biodegradability, it can be disposed to the soil without paying additional treatment costs. Therefore, efforts are continuing to find environmentally alternatives to reduce the pressure on the environmental components that suffer from the accumulation of waste, including the toxic of traditional batteries.

\section{Conflict of interest}

The authors declare that they have no conflict of interest.

\section{References}

[1] Fraiwan A, Kwan L, Choi S, A disposable power source in resource-limited environments: A paper-based biobattery generating electricity from wastewater, Biosens. Bioelectron, 2016, 85, 190-197. https://doi.org/10.1016/j.bios.2016.05.022.

[2] Leijonmarck S, Cornell A, Lindbergh G, Wagberg L, Single-paper flexible Li-ion battery cells through a paper-making process based on nanofibrillated cellulose J. Mater. Chem. A., 2013, 1, 4671. https://doi.org/10.1039/c3ta01532g.

[3] Esquivel JP, Castellarnau M, Gasso S, Sabate N, Paper-based batteries as sustainable power source for disposable electronic devices, Smart Systems Integration; 13th International Conference and Exhibition on Integration Issues of Miniaturized Systems, Barcelona, Spain, 2019, pp. 1-4.

[4] Esquivel JP, Alday P, Ibrahim OA, Fernández B, Kjeang E, Sabaté N, A Metal-Free and Biotically Degradable Battery for Portable Single-Use Applications, Advanced energy material, 2017, 7, 1700275. https://doi.org/10.1002/aenm.201700275.

[5] Larcher D, Tarascon JM, Towards Greener and More Sustainable Batteries for Electrical Energy Storage, Nature Chemistry, 2015, 7(1):19-29. https://doi.org/10.1038/nchem.2085.

[6] Nie Z, Nijhuis CA, Gong J, Chen X, Kumachev A, Martinez AW, Narovlyansky M, Whitesides GM, Electrochemical sensing in paper-based microfluidic devices, Lab on a Chip. 2010, 10(4), 477-483. https://doi.org/10.1039/B917150A.

[7] Scrosati B, Hassoun J, Sun Y, Lithium-ion batteries. A look into the future Energy \& Environmental Science. 2011, 4(9), 3287-3295. https://doi.org/10.1039/c1ee01388b.

[8] Hui SK, Zeng LH, Liu Y, The status and progress of resource utilization technology of e-waste pollution in China, Procedia Environmental Sciences, 2012, 16, 515 - 521. https://doi.org/10.1016/j.proenv.2012.10.071.

[9] González A, Goikolea E, Barrena JA, Mysyk R, Review on supercapacitors: Technologies and materials Renewable and Sustainable Energy Reviews. 2016, 58, 1189-1206. https://doi.org/10.1016/j.rser.2015.12.249.

[10] Mohammadifar M, Yazgan I, Zhang J, Kariuki V, Sadik OA, Choi S, Green Biobatteries: Hybrid Paper-Polymer Microbial Fuel Cells, Advanced sustainable system, 2018, (2),10. https://doi.org/10.1002/adsu.201800041.

[11] Zolina L, Destroa M, Curtilb D, Chaussyb D, Penazzia N, Beneventib D, Gerbaldi C, Flexible Cellulose-Based Electrodes: Towards Eco-friendly All-paper Batteries, Chemic al engineering transactions, 2014, 41, 361-366.

[12] Yao B, Yuan L, Xiao X, Zhang J, Qi Y, Zhou J, Zhou J, Hu B, Chen W, Paper-based solid-state supercapacitors with pencil-drawing graphite/polyaniline networks hybrid electrodes, Nano Energy. 2013, 2(6), 1071-1078. https://doi.org/10.1016/j.nanoen.2013.09.002.

[13] Jabbour L, Bongiovanni R, Chaussy D, Cellulose-based Li-ion batteries: a review. Cellulose, 2013, 20, 1523-1545. https://doi.org/10.1007/s10570013-9973-8.

[14] Jo JH, Jo CH, Qiu Z, Yashiro H, Shi L, Wang Z, Yuan S, Myung ST, Nature-Derived Cellulose-Based Composite Separator or Sodium-Ion Batteries. Front. Chem, 2020, 8:153 https://doi.org/10.3389/fchem.2020.00153.

[15] Fraiwan A, Choi S, Bacteria-Powered Battery on Paper, Physical Chemistry Chemical Physics, 2014, 16(47), 1-7. https://doi.org/10.1039/C4CP04804K.

[16] Fraiwana A , Kwanb L, Seokheun Choi S, A Disposable Power Source in Resource-limited Environments: A Paperbased Biobattery Generating Electricity from Wastewater, Biosensors \& Bioelectronics, 2016, 85. https://doi.org/10.1016/j.bios.2016.05.022.

[17] Chiapponea A, Naira JR, Gerbaldib C, Jabbourc L, Bongiovannia R, Zenod E, Microfibrillated cellulose as reinforcement for Li-Ion battery polymer electrolytes with excellent mechanical stability. J. Power Sources. 2011, 196, 10280-10288. https://doi.org/10.1016/j.jpowsour.2011.07.015.

[18] Lee YH, Kim JS, Noh J, Lee I, Kim HJ, Choi S, Seo J, Jeon S, Kim TS, Lee JY, Wearable Textile Battery Rechargeable by Solar Energy. NanoLetters 2013, 13, 5753-5761. https://doi.org/10.1021/nl403860k.

[19] Kim JY, Kim SK, Lee SJ, Lee SY, Lee HM, Ahn S, Preparation of micro-porous gel polymer for lithium ion polymer battery. Electrochim. Acta, 2004, 50, 363-366. https://doi.org/10.1016/j.electacta.2004.01.131.

[20] Stoppa M, Chiolerio A, Wearable Electronics and Smart Textiles: A Critical ReviewSensors. 2014, 14(7), 11957-11992. https://doi.org/10.3390/s140711957.

[21] Nguyen TH, Fraiwan A, Choi S, Paper-based batteries: A review, Biosensors and Bioelectronics, 2014, 54 640-649 https://doi.org/10.1016/j.bios.2013.11.007.

[22] Phillips ST, Lewis GG, Papertronic A, On-demand and Disposable Biobattery: Saliva-activated Electricity Generation from 5 Lyophilized Exoelectrogens Pre-inoculated on PaperExpert Rev. Mol. Diagn., 2014, 14, 123.

[23] Torres CI, Marcus AK, Lee H, Parameswarn P, Krajmalnik BR, Rittmann BE, kinetic A perspective on extracellular electron transfer by anoderespiring bacteriaFEMS Microbiol Rev., 2010. 34, 3. https://doi.org/10.1111/j.1574-6976.2009.00191.x.

[24] Logan BE, Exoelectrogenic bacteria that power microbial fuel cells. Nat Rev Microbiol, 2009, 7: 375-381. https://doi.org/10.1038/nrmicro2113.

[25] Lovley DR, The microbe electric: conversion of organic matter to electricity. Curr Opin Biotech, 2008, 19: 1-8. https://doi.org/10.1016/j.copbio.2008.10.005

[26] Zhong Q, Zhong J, Hu B, Hu Q, Zhou J, Wang ZL, A paper-based nanogenerator as a power source and active sensor, Energy Environ. Sci., 2013, 6, 1779. https://doi.org/10.1039/c3ee40592c

[27] Goodenough JB, Park KS, The Li-Ion Rechargeable Battery: A Perspective, J. Am. Chem. Soc. 2013, 135, 1167-1176. https://doi.org/10.1021/ja3091438. 